\title{
Ultrasound-Assisted Lumbar Puncture in a Neuromuscular Clinic has a High Success Rate and Less Pain
}

\author{
Alon Abraham, Ari Breiner, Hans D. Katzberg, Leif E. Lovblom, Vera Bril
}

\begin{abstract}
Background: Lumbar puncture (LP) performed with the assistance of ultrasound (US) may improve success rate, with fewer puncture attempts and less pain. Objectives: To explore the utility of US-assisted LP in a neuromuscular clinic. Methods: We performed a prospective, randomized, open-label study between May 2016 and January 2017. The primary outcome measure was LP success rate, and the secondary outcome measures included procedure time, number of attempts, and the levels of pain, anxiety, and satisfaction. Results: Lumbar puncture was performed in 40 consecutive patients. Ultrasound-assisted LP had a 100\% success rate, compared with $85 \%$ (95\% confidence interval: 58\%-96\%) without US assistance, although this difference failed to reach statistical significance. Ultrasound-assisted LP was associated with less pain and, also in patients $>60$ years of age, with fewer needle insertions. Both groups reported high satisfaction rates, regardless of the use of US. Conclusion: Ultrasound-assisted LP has a high success rate and less pain than unassisted LP, and can be accomplished easily in the outpatient neuromuscular clinic setting equipped with US.
\end{abstract}

RÉSUMÉ: Des examens de ponction lombaire assistés par des appareils à ultrasons et menés dans une clinique neuromusculaire ont obtenu des taux de succès élevés et entraîné moins de douleurs. Contexte: En plus de diminuer le nombre de tentatives de ponction alors nécessaires et la douleur qui en résulte, il est possible qu'un examen de ponction lombaire effectué avec l'aide d'appareils à ultrasons obtienne un plus haut taux de réussite. Objectifs: Dans le cadre d'une clinique neuromusculaire, se pencher sur l'utilité des examens de ponction lombaire assistés par des appareils à ultrasons. Méthodes: De mai 2016 à janvier 2017, nous avons mené une étude prospective sans insu à répartition aléatoire. La principale mesure de nos résultats a porté sur le taux de succès des examens de ponction lombaire. D'autres mesures de résultats ont inclus les aspects suivants: la durée des examens, le nombre de tentatives de ponction ainsi que les niveaux de douleur, d'anxiété et de satisfaction des patients. Résultats: Des examens de ponction lombaire ont été effectués chez 40 patients consécutifs. Ceux menés à l'aide d'appareils à ultrasons ont donné à voir un taux de succès de $100 \%$ comparativement à $85 \%$ (IC $95 \%: 58 \%$ - $96 \%$ ) dans le cas de ceux effectués sans ces appareils. Rappelons toutefois que cette différence ne s'est pas révélée significative sur le plan statistique. Les examens de ponction lombaire au moyen d'appareils à ultrasons ont aussi été associés à moins de douleurs ressenties et, chez des patients âgés de plus de 60 ans, à moins d'insertions d'aiguilles. Enfin, ces deux groupes ont rapporté des taux de satisfaction élevés, et ce, sans égard à l'utilisation d'appareils à ultrasons. Conclusions: Les examens de ponction lombaire assistés par des appareils à ultrasons possèdent un haut taux de succès et entraînent moins de douleurs que ceux menés sans ces appareils. Ils peuvent aussi être effectués facilement dans le cadre de cliniques neuromusculaires externes qui en sont munies.

Keywords: Lumbar puncture, Success rate, Ultrasound, Pain, Anxiety, Satisfaction

doi:10.1017/cjn.2018.351

Can J Neurol Sci. 2019; 46: 79-82

\section{INTRODUCTION}

Lumbar puncture (LP) is a common diagnostic test which allows access to the subarachnoid space in order to obtain CSF. CSF analysis provides useful diagnostic information in infectious, inflammatory, and neoplastic diseases affecting the peripheral and central nervous systems. In addition, LP may be used for therapeutic reasons such as reducing intracranial pressure by CSF removal, or delivery of drugs to the central nervous system. ${ }^{1,2}$

Ultrasound (US) imaging of the lumbar spine can assist in performance of the LP, particularly in patients with anatomic landmarks that are difficult to palpate. Recent studies have shown that LP with US assistance improves the success rate, reduces the number of required attempts in order to obtain CSF, and decreases pain scores. ${ }^{3}$ However, most of these studies were performed in an emergency or anesthesiology department setting, and a few studies have failed to show any advantages of US-assisted LP. ${ }^{3-5}$ The use of US imaging has expanded in the neuromuscular field, leading to increased availability of equipment and familiarity with

From the Neuromuscular Diseases Unit of the Department of Neurology, Tel Aviv Sourasky Medical Center, the Sackler Faculty of Medicine, Tel Aviv University, Tel Aviv, Israel (AA); Division of Neurology, The Ottawa Hospital and University of Ottawa, Ottawa, Ontario, Canada (AB); Ellen and Martin Prosserman Centre for Neuromuscular Diseases, Division of Neurology, Department of Medicine, University Health Network, University of Toronto, Toronto, Canada (HDK, VB); Division of Endocrinology and Metabolism, Department of Medicine, Sinai Health System, Lunenfeld Tanenbaum Research Institute, University of Toronto, Toronto, Canada (LEL).

Received March 6, 2018. Final Revisions Submitted August 30, 2018. Date of ACCEPTANCE SEPTEMBER 7, 2018.

Correspondence to: Alon Abraham, Neuromuscular Diseases Unit of the Department of Neurology, Tel Aviv Sourasky Medical Center, the Sackler Faculty of Medicine, Tel Aviv University, Tel Aviv, Israel. Email: alonabmail@gmail.com 
the technique. In the current study, we aimed to explore prospectively the utility of US-assisted LP in an outpatient neuromuscular clinic. We hypothesized that using US-assisted LP in the neuromuscular clinic has similar or greater benefits compared with its use in other settings.

\section{MATERIALS AND METHODS}

We performed a prospective randomized open-label study between May 2016 and January 2017 on LP performed with and without US assistance. All LP procedures were performed at the Prosserman Family Neuromuscular Clinic, Toronto General Hospital, University Health Network, Toronto, Canada. The Research Ethics Board of the University Health Network approved the study protocol and all patients signed an informed consent.

A total of 40 patients underwent LP as part of the study, of which 20 patients underwent US-assisted LP, whereas 20 patients underwent routine unassisted LP. The first and last 10 consecutive patients underwent LP with the assistance of US, whereas the remaining 20 consecutive patients underwent unassisted LP. This specific allocation scheme was arbitrarily determined.

The primary outcome measure of the study was the LP success rate, as defined by the success in obtaining CSF. Secondary outcome measures included procedure time, number of LP needle insertions, the levels of patient pain and anxiety during the procedure, and overall patient satisfaction score. Primary and secondary outcome measures were compared between unassisted and US-assisted LP groups in the total cohort, and in two subgroups including older patients ( $>60$ years of age), and patients with overweight (body mass index $[\mathrm{BMI}]>25 \mathrm{~kg} / \mathrm{m}^{2}$ ). As a higher rate of unsuccessful LP is expected within these groups, ${ }^{6,7}$ the yield of US-assisted LP is of importance in these populations. Inclusion criteria included age $\geq 18$ years, the ability to understand and cooperate with the study procedure, and provision of an informed consent before entering the study. Exclusion criteria included serious or unstable medical or psychological conditions, local infection at the puncture level, known coagulopathy, low platelet counts $\left(<80,000 / \mathrm{mm}^{3}\right)$, international normalized ratio $>1.5$, or anticoagulant treatment.

In patients undergoing US-assisted LP, the interspinous space was identified using the assistance of the ultrasound device (General Electric LOGIQ S7 Expert, Toronto, Canada), and a convex transducer with a low frequency of $5 \mathrm{MHz}$ (ML2-5). The interspinous space was marked by a pen. Midline identification was performed with the probe in the transverse plane, while the interspinous space was identified by rotating the probe to the sagittal plane. Ultrasound imaging was performed before the LP only, and was not used for real-time US guidance, and therefore was not done under sterile conditions.

In patients undergoing unassisted LP, the interspinous space was identified by palpation. Lumbar puncture was performed under sterile conditions. The skin and the subcutaneous tissues were infiltrated with local anesthetic (lidocaine 2\%) to minimize pain and discomfort during the procedure. The patients were positioned in the left lateral decubitus position, with hips and knees flexed, the back aligned near the edge of the bed, and a pillow placed under the head. The puncture was performed at the L3-L4 interspinous space corresponding to the axial plane of the iliac crests, or at the space just above or below. Physicians or patients were not blinded to US use. Before study initiation, the examiner (AA) observed several US-assisted epidural blocks in the anesthesiology department, in order to gain familiarity with US imaging of the spine.

The LP success rate was defined as the success in obtaining CSF. Dry or traumatic taps were considered as procedure failures. The procedure time was defined as the time from skin puncture by the LP needle, to the appearance of CSF in the needle.

\section{Visual Analog Pain, Anxiety, and Satisfaction Scales}

The visual analog pain, anxiety, and satisfaction scales were used to record the subjects' experience during the procedure, without influencing their response by using descriptive terms. The patients were asked to rate their pain, anxiety, and satisfaction on a visual scale ranging from $0 \mathrm{~cm}$ (no pain or anxiety, complete dissatisfaction) to $10 \mathrm{~cm}$ (worst possible pain or anxiety, complete satisfaction).

\section{Statistical Analysis}

Statistical analysis was performed using SAS version 9.2 for Windows (SAS Institute, Cary, NC, USA). A sample size of 20 patients in each group was calculated based on a power of 0.80 to demonstrate a $31 \%$ difference between groups. Although LP success rates vary significantly between studies, ${ }^{3}$ success rates as low as $65 \%$ have been reported. ${ }^{8}$ We assumed a worst-case scenario of a success rate of only $60 \%$ for purposes of this study. Demographic data, success rate, procedure time, and scale scores were compared between unassisted and US-assisted LP groups using the Student's $t$-test, the Wilcoxon rank-sum test, or Fisher's exact test, depending on the type of data. A $95 \%$ confidence interval (CI) was calculated for the primary study outcome which was defined as the success rate using the Wilson score interval method. The same comparisons were made in two subpopulations: (1) patients $>60$ years of age and (2) patients with BMI $>25\left(\mathrm{~kg} / \mathrm{m}^{2}\right)$. $p$-value $<0.05$ was considered as statistically significant.

\section{RESULTS}

Lumbar puncture was performed in 40 consecutive patients by a single examiner (AA) after obtaining an informed consent. The most common indication for the procedure was suspected chronic inflammatory demyelinating polyneuropathy. The mean age of the total cohort was $59 \pm 15$ years, with male preponderance (75\%). Patients in the US-assisted LP group had lower BMI $\left(25.9 \pm 3.2\right.$ vs. $29 \pm 4.7 \mathrm{~kg} / \mathrm{m}^{2}$ correspondingly; $\left.p=0.03\right)$. There were no differences in any other characteristics between groups, except for lower pain levels in patients in the US-assisted LP group ( $2.4 \pm 2.1$ vs. $4.1 \pm 2.4$ correspondingly; $p=0.03)$, and high satisfaction rates were reported by both groups, regardless of the use of US. Patients in the US-assisted LP group had a $100 \%$ success rate compared with $85 \%$ in the non-US-assisted group (95\% CI: $64 \%-95 \%$ ), although this finding failed to reach statistical significance using the Fisher's exact test $(p=0.23)$ (Table 1). Although not measured formally, the estimated mean additional time required for US-assisted LP compared with non-US-assisted LP, including turning on the machine, localizing, and marking the skin, was 10-15 minutes. In a subgroup analysis of patients $>60$ years of age, BMI was not different between groups, but patients in the US-assisted LP group had less pain and fewer needle 
Table 1: Characteristics of 40 patients undergoing lumbar puncture with and without US assistance

\begin{tabular}{l|c|c|c}
\hline & Standard LP $(\boldsymbol{n = 2 0})$ & US assisted $(\boldsymbol{n = 2 0})$ & $\begin{array}{c}\boldsymbol{p} \text { - } \\
\text { value }\end{array}$ \\
\hline Age (years) & $63 \pm 12$ & $56 \pm 17$ & 0.14 \\
\hline Gender $(\%$ females) & 35 & 15 & 0.14 \\
\hline BMI $\left(\mathrm{kg} / \mathrm{m}^{2}\right)$ & $29 \pm 4.7$ & $25.9 \pm 3.2$ & 0.03 \\
\hline Success rate $(95 \% \mathrm{CI})$ & $85 \%(64 \%-95 \%)$ & $100(100 \%)$ & 0.23 \\
\hline Time (seconds) & $68.7 \pm 64.2$ & $84.0 \pm 57.8$ & 0.48 \\
\hline Needle insertions & $1.7 \pm 1$ & $1.3 \pm 0.5$ & 0.12 \\
\hline Pain $(0-10)$ & $4.1 \pm 2.4$ & $2.4 \pm 2.1$ & 0.03 \\
\hline Anxiety $(0-10)$ & $3.1 \pm 2.4$ & $4.3 \pm 2.6$ & 0.15 \\
\hline Satisfaction $(0-10)$ & $8.7 \pm 1.9$ & $9 \pm 1.7$ & 0.88 \\
\hline
\end{tabular}

$\mathrm{BMI}=$ body mass index $\mathrm{CI}=$ confidence interval $\mathrm{LP}=$ lumbar puncture; US $=$ ultrasound .

insertions (Table 2). In a subgroup analysis of patients with BMI $>25 \mathrm{~kg} / \mathrm{m}^{2}$, those in the US-assisted LP group had lower BMI, and no differences in other characteristics, except a trend toward lower pain levels (Table 2).

\section{DISCUSSION}

Our study results show that US-assisted LP in the neuromuscular outpatient clinic had a high success rate of $100 \%$. Although a lower success rate of $85 \%$ (95\% CI: $64 \%-95 \%$ ) was found in LP done without US group, this difference failed to reach statistical significance $(p=0.23)$. The lack of difference might be related to the relatively small number of patients in the presence of relatively small differences between groups, as the LP success rate was relatively high in both groups. The expertise of the single examiner may have led to an unexpectedly high success rate in the unassisted LP group. The high success rate of US-assisted LP in the current study is similar to or better than reported in most other studies. ${ }^{3}$ Nonetheless, lower success rates of US-assisted LP have been reported in some studies. ${ }^{4,5} 8$ This finding suggests that US is operator-dependent, and the success of US-assisted LP in the current study might be partially explained by the familiarity of the examiner with US imaging in the neuromuscular clinic setting. In addition, in agreement with previous studies, ${ }^{3}$ we found that LP with US assistance was associated with less pain. Although this difference might be partially explained by a lower BMI in the USassisted LP group, a similar difference in pain levels was also observed in patients above 60 years of age having a similar BMI. Older patients also required fewer LP attempts when once US assistance was used for LP, despite similar BMI, compared with unassisted patients. Interestingly, both groups reported high satisfaction rates regardless of the use of US. However, satisfaction is a non-specific estimation, expressing components beyond the procedure itself, such as satisfaction from the treating physicians, administration staff, and clinic facilities. As LP without US assistance had relatively high success rates and low pain scores in this study, the cost-effectiveness of US assistance needs to be considered. However, if US equipment is already available and the clinic staff is familiar with US imaging, as is the case in some neuromuscular clinics, US-assisted LP might become more costeffective. Nonetheless, it should be noted that US-assisted LP
Table 2: Characteristics of older patients and patients with BMI > 25 undergoing lumbar puncture with and without US assistance

\begin{tabular}{l|c|c|c}
\hline & Standard LP & US assisted & $\boldsymbol{p}$-value \\
\hline Patients $>60$ years of age & & & \\
\hline$N$ & 13 & 10 & \\
\hline Age (years) & $70 \pm 5$ & $69 \pm 6$ & 0.80 \\
\hline Gender $(\%$ females) & 8 & 10 & 0.79 \\
\hline BMI $\left(\mathrm{kg} / \mathrm{m}^{2}\right)$ & $27.8 \pm 3.4$ & $26.9 \pm 3.3$ & 0.42 \\
\hline Success rate $(95 \% \mathrm{CI})$ & $85 \%(58 \%-96 \%)$ & $100(100 \%)$ & 0.49 \\
\hline Time $(\mathrm{s})$ & $68.4 \pm 72.8$ & $71.7 \pm 38.5$ & 0.78 \\
\hline Needle insertions & $1.7 \pm 1$ & $1 \pm 0$ & 0.045 \\
\hline Pain $(0-10)$ & $3.8 \pm 2.7$ & $1.2 \pm 1.2$ & 0.03 \\
\hline Anxiety $(0-10)$ & $2.5 \pm 2.6$ & $3.4 \pm 2.7$ & 0.29 \\
\hline Satisfaction $(0-10)$ & $8.9 \pm 1.8$ & $9.5 \pm 0.7$ & 0.97 \\
\hline Patients with BMI $>25\left(\mathrm{~kg} / \mathrm{m}^{2}\right)$ & & & \\
\hline$N$ & 14 & 14 & \\
\hline Age (years) & $63 \pm 11$ & $58 \pm 14$ & 0.64 \\
\hline Gender $(\%$ females) & 29 & 7 & 0.16 \\
\hline BMI (kg/m $\left.{ }^{2}\right)$ & $31 \pm 4.2$ & $27.7 \pm 1.9$ & 0.02 \\
\hline Success rate $(95 \% \mathrm{CI})$ & $86 \%(60 \%-96 \%)$ & $100(100 \%)$ & 0.48 \\
\hline Time (seconds) & $81.2 \pm 70.2$ & $76.3 \pm 64.5$ & 0.90 \\
\hline Needle insertions & $1.6 \pm 0.9$ & $1.1 \pm 0.3$ & 0.07 \\
\hline Pain $(0-10)$ & $3.4 \pm 2.5$ & $1.5 \pm 1$ & 0.054 \\
\hline Anxiety $(0-10)$ & $2.7 \pm 2.2$ & $3.9 \pm 2.4$ & 0.28 \\
\hline Satisfaction $(0-10)$ & $8.7 \pm 2$ & $9.5 \pm 0.9$ & 0.42 \\
\hline
\end{tabular}

$\mathrm{BMI}=$ body mass index $\mathrm{CI}=$ confidence interval $\mathrm{LP}=$ lumbar puncture; $\mathrm{US}=$ ultrasound

success rates differ between examiners in different studies, ranging from $70 \%$ to $100 \%{ }^{3}$ so this experience needs to be considered when US assistance for LP is advised in individual patients.

The main limitations of our study are the relatively low number of patients, and the high success rate in both groups, so that our results failed to demonstrate statistically significant differences regarding LP success, the primary study outcome. However, the confidence interval of the unassisted LP group fell below the success rate in the US-assisted group, and this tends to support using US for a better outcome. We expected a lower success rate of $75 \%$ in the unassisted group that would have shown a difference with using US that did not happen. With the current study success rates, modeling predicts that approximately a twofold increase in the number of patients (i.e., $\geq 74$ ) is required in order to prove a statistically significant difference in outcomes. In addition, we did not perform US-assisted LP after the failure of unassisted LP, and therefore cannot address the utility of USassisted LP in these cases. We compared the time from LP needle insertion to CSF appearance at the proximal part of the needle, and did not compare the overall procedure time, which is likely to be longer in the US-assisted LP group. Finally, this study reports the experience of a single examiner in a highly operator-dependent procedure, and therefore might not be generalizable to other examiners and clinics. 
In conclusion, US-assisted LP has a high success rate and less pain than unassisted LP, and is feasible in a neuromuscular clinic that is properly equipped and familiar with US imaging techniques.

\section{ACKNOWLEDGMENTS}

No funding was received in the publication of this article.

\section{Disclosures}

AA, AB, LEL, and VB have nothing to disclose. HDK reports grants and personal fees from CSL Behring, personal fees from Octapharma, grants from Genzyme, personal fees from Terumo, personal fees from Flexpharma, outside the submitted work.

\section{Statement of Authorship}

Alon Abraham: study concept and design, analysis and interpretation of data;

Ari Breiner: study concept and design, acquisition of data, study supervision, critical revision of manuscript for intellectual content, analysis and interpretation of data;

Carolina Barnett: acquisition of data, analysis and interpretation of data;

Hans D. Katzberg: study concept and design, acquisition of data;

Leif E. Lovblom: study concept and design, analysis and interpretation of data
Vera Bril: study concept and design, analysis and interpretation of data, study supervision, critical revision of manuscript for intellectual content

\section{REFERENCES}

1. Wright BLC, Lai JTF, Sinclair AJ. Cerebrospinal fluid and lumbar puncture: a practical review. J Neurol [online serial]. 2012;259:1530-45; Accessed at: http://link.springer.com/ 10.1007/s00415-012-6413-x

2. Sempere AP, Berenguer-Ruiz L, Lezcano-Rodas M, Mira-Berenguer F, Waez M. Lumbar puncture: its indications, contraindications, complications and technique. Rev Neurol. 2007:433-6.

3. Soni NJ, Franco-Sadud R, Schnobrich D, et al. Ultrasound guidance for lumbar puncture. Neurol Clin Pract. 2016;6:358-68.

4. Nomura JT, Leech SJ, Shenbagamurthi S, et al. A randomized controlled trial of ultrasound-assisted lumbar puncture. J Ultrasound Med. 2007;26:1341-8.

5. Peterson MA, Pisupati D, Heyming TW, Abele JA, Lewis RJ. Ultrasound for routine lumbar puncture. Acad Emerg Med. 2014;21:130-6.

6. Edwards C, Leira EC, Gonzalez-Alegre P. Residency training: a failed lumbar puncture is more about obesity than lack of ability. Neurology. 2015;84:e69-72.

7. Barreras P, Benavides DR, Barreras JF, et al. A dedicated lumbar puncture clinic: performance and short-term patient outcomes. J Neurol. 2017;264:2075-80.

8. Sahin SH, Colak A, Arar C, Yildirim I, Sut N, Turan A. Modified 45-degree head-up tilt increases success rate of lumbar puncture in patients undergoing spinal anesthesia. J Anesth. 2014;28: 544-8. 